\title{
Emotional Intelligence and Social-Emotional Learning: An Overview
}

\author{
Anamitra Basu \\ Indian Institute of Technology, Bhubaneswar, India
}

\author{
Martial Mermillod \\ Clermont Université, Clermont-Ferrand, France
}

\begin{abstract}
The term "EI (emotional intelligence)" was first used in 1990 by Salovey and Mayer. EI involves: (1) the ability to perceive accurately, appraise and express emotion; (2) the ability to access and/or generate feelings when they facilitate thought; (3) the ability to understand emotion and emotional knowledge; and (4) the ability to regulate emotions to promote emotional and intellectual growth. Adequate interpersonal skills are an important component of EI. Social skills include: interpersonal behaviors needed to make and keep friends, such as joining in and giving compliments; peer-related social skills valued by classmates, such as sharing and working cooperatively; teacher-pleasing social skills related to academic success, such as listening and following directions; self-related behaviors, such as following through and dealing with stress; communication skills, such as attending to the speaker; and assertiveness skills. IE may be as important as or even more important than cognitive intelligence. Many learners, particularly those at risk of school failure, do not possess the social-emotional skills needed to be emotionally intelligent. Social-emotional learning enables learners to effectively understand process, manage and express the social and emotional aspects of their lives.
\end{abstract}

Keywords: EQ (emotional quotient), EI (emotional intelligence), competence questionnaire, EQI (emotional quotient inventory), social emotional skills

\section{Introduction}

Salovey and Mayer (1990) identified five domains of EI (emotional intelligence), namely, self-awareness, managing emotions, motivating oneself, empathy and handling relationships, which help to understand emotional learning personally. There are the details of these five characteristics for having high EI:

(1) Self-awareness-knowing and recognizing one's emotions;

(2) Mood management-managing one's feelings to the present situation and reacting accordingly;

(3) Self-motivation-directing oneself towards a goal, despite of having self-doubt, inertia and impulsiveness;

(4) Empathy—recognizing others' feelings and turning them into their verbal and non-verbal cues;

(5) Managing relationships—-managing interpersonal interaction and successful negotiations.

ESAP (Nelson and Low's Emotional Skill Assessment Process) relates with the earlier concept. It is highly personal and unique to each person. EI tests are designed to quantify EI. The result of the test is often given as EQ (emotional quotient). The higher the EQ, the more competent the person is with self-understanding

\footnotetext{
Anamitra Basu, Ph.D., assistant professor, School of Humanities, Social Sciences and Management, Indian Institute of Technology.

Martial Mermillod, Ph.D., professor, LAPSCO-UMR CNRS, Clermont Université.
} 
and general social situations. A large publication of EQ tests is probably more needed than the actual large publication of IQ (intelligence quotient) test. Three popular EQ tests are the MSCEIT (Mayer-Salovey-Caruso EI test), the ECI (emotional competence inventory) and the EQI (emotional quotient inventory). The authors of the MSCEIT originally developed the MEIS (multifactor EI scale), while some other authors developed the COMET/EQ (competence/ emotional quotient) questionnaire, the EQ-map.

The relation between EQ and personality tests is also envisaged. These analyze a person's personality with a broader scope, e.g., the E-PQR (eysenck personality questionnaire revised) used intro- or extro- version, neurotic, psychotic and truthfulness.

EI has a long impact and it is becoming indispensible for many parents and educators who are alarmed by increasing levels of conflict in young schoolchildren. Nevertheless, EI has been included in training programs of corporate employees for better motivation which will automatically increase productivity and profits.

Intrapersonal skills and interpersonal skills are essential for self-esteem. Relationship skills are essential measure of emotional control and management. Three major ingredients of relationship skills are assertion, anger control and management in addition with fear control and management. Drive strength, time management, commitment ethic and positive personal change are the major four essential emotional skills for self-management. Transformative learning is essential for understanding the emotional mind. The synergy of emotive and cognitive mind gives rise to emotionally intelligent behavior.

\section{Measures of EI}

Maximal performance mainly is the ability based on measure and mixed-model measures, emphasizing on typical performance (Mayer, Salovey, \& Caruso, 2000; Petrides \& Furnham, 2000). Maximal performance indicates the best cognitive performance that a test-taker can achieve in a test, while typical performance is a measure of a test-taker's performance under ordinary test conditions.

The EI appraisal measures:

(1) Personal competence, including: (a) Self-awareness: Recognizing and understanding one's emotions in the moment as well as the tendencies across time and situation; and (b) Self-management: Using awareness of emotions to manage response to different situations and people;

(2) Social competence, including: (a) Social awareness: Understanding the perspectives of other people including their motivations, their emotions and the meaning of what they do and say; and (b) Relationship management: Using awareness of one's own emotions and the emotions of others to manage relationships to a successful outcome.

Face validity is an estimate to measure whether a test purports to measure a certain criterion. When a test is subject to faking, low face validity may make the test more valid. The MSCEIT measure is a measure of EI, which involves a series of emotion-based problem-solving items with low face-validity (MacCann, Roberts, Matthews, \& Zeidner, 2004; Roberts, Zeidner, \& Matthews, 2001). The various domains in which MSCEIT is applicable are: (1) experiential area, including perceiving emotions and facilitating thinking; and (2) strategic area, including understanding emotional meaning and managing emotions. EI helps to perceive the emotion, facilitate thinking process, comprehend meaning of emotion and manage emotions skillfully.

Response set is responding in a desirable way. This can be situational and temporary. On the contrary, response style is a more long-term trait-like quality. Considering the context's certain self-report EI inventories are used (e.g., in employment settings), the problems of response sets in high-stakes scenarios become clear. If 
we consider inherent similarities, it may be reasonable to assert that socially desirable responding has the capacity to contaminate responses on self-report EI measures.

Positive behaviors include positive self-esteem, meaningful goal achievement, dependability, effective communication, constructive thinking, emotional self-control, problem-solving skills and healthy stress management skills involving higher psychological processes and the integration of cognitive and emotional minds. Effective education involving the development of personal responsibility skill and proper education experience encompasses specific learning experiences to help students develop the EI skills essential to academic achievement, personal well-being and career/life effectiveness. This broader definition of education emphasizes on the "right mind". But, we should value both minds and integrate emotional mind with cognitive mind. Higher psychological processes balance two minds.

The key feature of developing EI is to educate two minds with a focus on how the cognitive and emotional mind work. Emotionally intelligent behavior is reflected in the ability to think constructively and behave wisely. Intentional and self-directed behavior needs reflective thoughts. Wise and effective behavior requires the ability to regulate and express emotions in healthy ways. EI skills harmonize the cognitive and emotional minds and are essential to effective behavior.

The area of affective neuroscience embarks upon the relationship of EI to academic achievement and personal well-being. The development of the brain during the period from early adolescence to young adulthood is very important for physical and emotional growth. The learning experiences given during this critical developmental period can positively influence the development of academic, career and life effectiveness skills.

Nelson and Low (2003) defined EI as a confluence of developed skills and abilities to: (1) accurately know oneself in terms of personal strengths and weaknesses; (2) establish and maintain effective and healthy relationships; (3) get along and work productively with others; and (4) deal effectively and healthily with the demands and pressures of daily living. The ESAP is the research based on assessment model. It is used to help students to identify and understand important EI skills.

Four distinct factors provided by the ESAP responsible for EI are: (1) interpersonal skills; (2) leadership skills; (3) self-management skills; and (4) intrapersonal skills. The specific EI skills that contribute to these factors are: (1) assertion; (2) social awareness; (3) empathy; (4) decision-making; (5) positive influence (leadership); (6) drive strength (goal setting); (7) commitment ethic (personal responsibility); (8) time management; (9) self-esteem; and (10) stress management. Interpersonal skills and intrapersonal skills depend upon social awareness, empathy, self-esteem and stress management. Leadership skills and self-management skills depend upon decision-making, empathy, positive influence, drive strength, commitment ethic, time management and stress management. Nelson and Low (2003) have related research establishing the relationship of EI skills to academic achievement (Nelson \& Low, 2003; Vela, 2002; D. Nelson \& K. Nelson, 2003; Stottlemyer, 2002). The ESAP scales of assertion, drive strength, commitment ethic, time management and stress management have proved to be significant predictors of academic success. Meaningful emotional learning is essential to understand the different functions and processes of the cognitive and emotional minds. One of the major principles of EI is personal leadership. Educational model of EI emphasizes comfort, empathy and decision-making and leadership are essential emotional skills and ingredients of personal leadership.

Epstein has demonstrated functions and processes associated with both the cognitive and emotional (experiential) mind. Epstein (1998) further emphasized that the emotional mind: (1) learns directly from experience; (2) thinks quickly for immediate action; (3) is holistic; (4) thinks in terms of associations; (5) is 
closely connected to emotions; (6) interprets experience and guides conscious thoughts and behaviors through "vibes" from past experiences; (7) sees the world in concrete images, metaphors and stories; (8) is experienced passively as if we are sized by our emotions; (9) experiences its beliefs as self-evidently valid (experiencing is believing); (10) pays attention only to outcome; (11) thinks in terms of broad categories; (12) operates in different modes corresponding to specific emotional states; and (13) changes slowly with repetitive or intense experience.

Epstein (1998) has also opined that the cognitive mind: (1) learns from abstract representations; (2) thinks slowly and deliberately and is oriented towards planning and consideration; (3) is analytic; (4) thinks in terms of causes and effects; (5) separates logic from emotions; (6) interprets experience through conscious appraisal of events; (7) sees the world in abstract symbols (words and numbers); (8) experiences actively and consciously (as if we are in control of our thoughts); (9) requires justification by logic and evidence (give me proof); (10) pays attention also to process; (11) thinks in terms of finer distinctions and gradations; (12) highly integrated and more internally consistent; and (13) changes rapidly.

\section{Conclusions}

Integrity of the emotional mind and the cognitive mind is essential for effective behavior. Negligence of one over the other leads to behavior that is incomplete. EI skills are higher psychological processes which balance the two minds for the achievement of academic success, career and work effectiveness and personal well-being.

Emotional illiteracy is reflected in failed marriages, troubled families and social lives. It deteriorates physical health and has its effect in the form of tragedies. The essential skill of EI has to be taught as indispensible similar to traditional measures like IQ.

Intrapersonal growth and development is incomplete without having high EI.

\section{References}

Cox, J., \& Nelson, D. (2004). The relationship of emotional intelligence skills and constructive thinking patterns (Unpublished Raw Data, Texas A \& M University-Kingsville).

Epstein, S. (1998). Constructive thinking: The key to emotional intelligence. Westport, C. T.: Prager.

MacCann, C., Matthews, G., Zeidner, M., \& Roberts, R. (2004). The assessment of emotional intelligence: On frameworks, fissures, and the future. In G. Geher (Ed.), Measuring emotional intelligence: Common ground and controversy (pp. 21-52). Hauppauge, N. Y.: Nova Science Publishers.

Mayer, J. D., Caruso, D., \& Salovey, P. (2000). Selecting a measure of emotional intelligence: The case for ability scales. In R. Bar-On, \& J. D. A. Parker (Eds.), The handbook of emotional intelligence: Theory, development, assessment and application at home, school and in the workplace (pp. 320-342). San Francisco: Jossey-Bass.

Nelson, D., \& Low, G. (2003). Emotional intelligence: Achieving academic and career excellence. Upper Saddle River, N. J.: Prentice-Hall.

Nelson, D., \& Nelson, K. (2003). Emotional intelligence skills: Significant factors in freshman achievement and retention. (ERIC Document Reproduction Service, No. CG032375).

Nelson, D., Jin, Y., \& Wang, X. H. (2002). Reliability and validity parameters for the Chinese version of the emotional skills assessment process (Unpublished raw data, East China Normal University).

Orstein, R. (1997). The right mind: Making sense of the hemispheres. New York: Harcourt Brace and Company.

Petrides, K. V., \& Furnham, A. (2000). Gender differences in measured and self-estimated trait emotional intelligence. Sex Roles, 42, 449-461.

Roberts, R. D., Zeidner, M., \& Matthews, G. (2001). Does emotional intelligence meet traditional standards for an "intelligence?” Some new data and conclusions. Emotion, 1, 196-231.

Roberts, R. D., Zeidner, M., \& Matthews, G. (2004). Does emotional intelligence meet traditional standards for an "intelligence”? Some new data and conclusions. In G. J. Boyle, \& D. H. Saklofske (Eds.), Psychology of individual differences (Vol. 3, Cognition, emotion and conation). Thousand Oaks, C. A.: Sage Publications.

Salovey, P., \& Mayer, J. D. (1990). Emotional intelligence. Imagination, Cognition, and Personality, 9, 185-211.

Stottlemyer, B. G. (2002). A conceptual framework for emotional intelligence in education: Factors affecting student achievement (Unpublished Doctoral Dissertation, Texas A \& M University-Kingsville).

Vela, R. (2003). The role of emotional intelligence in the academic achievement of first year college students (Unpublished Doctoral Dissertation, Texas A \& M University-Kingsville). 